\title{
The time course of perceptual grouping: The role of segregation and shape formation
}

\author{
IRENE RAZPURKER-APFELD AND RUTH KIMCHI \\ University of Haifa, Haifa, Israel
}

\begin{abstract}
The time course of perceptual grouping was examined in two experiments, using a primed matching task. In different conditions, elements were grouped into columns/rows by common lightness, into a shape (triangle/ arrow or square/cross) by common lightness, and into a shape without segregation of elements. The results showed an early and rapid grouping into columns/rows by common lightness and into a shape when no segregation from other elements was involved. Goodness of shape (i.e., triangle/arrow vs. square/cross) had no influence on how early grouping was evident, but the relatively poorer shapes appeared to consolidate with time. In contrast, grouping into a shape that involved segregation and required resolving figure-ground relations between segregated units, as grouping into a shape by common lightness, consumed time, regardless of shape goodness. These results suggest that the time course of grouping varies as a function of the processes involved in it (e.g., segregation and shape formation) and the conditions prevailing for each process.
\end{abstract}

Visual objects, as we phenomenologically perceive them, are not afforded directly by the retinal image. Internal processes of organization must then be responsible for structuring the bits and pieces of visual information into the coherent units that we experience as environmental objects. The Gestalt psychologists suggested that perceptual organization is achieved by grouping elements together by virtue of certain properties that are present in the image, including proximity, closure, good continuation, common motion, and similarity (Wertheimer, 1923/1955). Recently, two more grouping principles have been added: grouping by common region (Palmer, 1992) and grouping by connectedness (Palmer \& Rock, 1994; Rock, 1986). Palmer and Rock argued for an even more basic grouping, grouping by uniform connectedness, which precedes all other forms of grouping. According to this principle, a connected region of uniform visual property (such as color, texture, and motion) is perceived initially as a single perceptual unit. In addition, it has been suggested that grouping involves two operations: unit formation, or clustering, which determines the belonging together of elements and their segregation from other elements, and configuring, or shape formation, which determines how the grouped elements appear as a whole, on the basis of interrelations among the elements (Gillam, 2005; Koffka, 1935; Rich \& Gillam, 2000; Rock, 1986; Trick \& Enns, 1997). Although shape formation presupposes unit formation, they may be different kinds of processes (Rock, 1986; Trick \& Enns, 1997).

Traditional theories of perception have considered perceptual grouping to be a unitary process that occurs at an early, preattentive stage of processing, providing the perceptual units to which attention is allocated for later, more elaborated processing (e.g., Marr, 1982; Neisser, 1967; Treisman, 1982). A growing body of research, however, has demonstrated that different groupings vary in their time course, attentional demands, and developmental progression (e.g., Behrmann \& Kimchi, 2003; Ben-Av \& Sagi, 1995; Hadad \& Kimchi, 2006; Kimchi, 1998, 2000; Kimchi, Hadad, Behrmann, \& Palmer, 2005; Kimchi \& Razpurker-Apfeld, 2004; Kurylo, 1997; Quinn, Bhatt, Brush, Grimes, \& Sharpnack, 2002).

Studies in which the time course of grouping in adult observers has been examined have focused on comparing groupings guided by different Gestalt principles. For example, Ben-Av and Sagi (1995) and Han (2004) have shown that grouping by proximity is achieved faster than grouping by similarity in luminance or in shape. Kurylo (1997) obtained evidence suggesting that grouping by proximity requires less time than does grouping by good continuity, although other studies have suggested that grouping by good continuation is likely to be accomplished by early perceptual processes (Behrmann \& Kimchi, 2003; Hadad \& Kimchi, 2006; Kimchi, 2000).

Research on the development of perceptual organization also has focused on comparing different grouping principles - in particular, their functional onset. For example, infant studies have indicated that grouping by common lightness is evident in 3-month-olds (Quinn et al., 2002; Quinn, Burke, \& Rush, 1993) and even in newborns (Farroni, Valenza, Simion, \& Umiltà, 2000) but that grouping by common shape becomes functional only at about 7 months (Quinn et al., 2002). Sensitivity to good continuation has recently been documented in 3- to 4-month-old

R.Kimchi, rkimchi@research.haifa.ac.il 
infants (Quinn \& Bhatt, 2005), but the ability to group line segments by good continuation appears to be highly constrained by proximity between the segments even at 5 years of age (Hadad \& Kimchi, 2006; Kovacs, 2000).

In this study, we examined the time course of grouping as a function of the operations involved in grouping. Of particular relevance to the present article, differential attentional demands have been found even when grouping was guided by the same Gestalt principle, depending on the processes involved in the grouping. In a study that examined grouping under conditions of inattention, Kimchi and Razpurker-Apfeld (2004) presented observers with two successive brief displays, each comprising a central target square surrounded by elements. The task was to judge whether the two targets were the same or different. The organization of the background elements stayed the same or changed, independently of the targets. They measured whether performance in the same-different task for the target was influenced by the background organization being the same or different over the two successive displays. The results showed that background elements grouped into columns or rows by common color (see also Russell \& Driver, 2005) and into a square or a cross when background elements were homogeneous. In contrast, there was no indication that background elements grouped by common color into a triangle/arrow or a square/cross. These findings were seen to suggest that grouping into a shape can take place without attention when no segregation of some elements from other elements is involved, depending on shape goodness. Grouping that involves segregation can also take place without attention when all the segregated units are designated as figures (as in grouping into columns/rows by common color), but not when resolving figure-ground relations between the segregated units is required (as in grouping into a shape by common color). An interesting question, addressed in the present study, is whether the time course of grouping also varies as a function of the processes involved in it.

A powerful tool for examining the time course of grouping is the primed matching paradigm (Beller, 1971). Unlike methods that rely on participants' reports about the product of grouping (e.g., Ben-Av \& Sagi, 1995; Kurylo, 1997), the primed-matching paradigm enables implicit assessment of observers' perceptual representations. Participants are presented with a priming stimulus followed immediately by a pair of test figures to which a same-different judgment is required. The time to respond correctly to same pairs is a function of the representational similarity between the test figures and the prime: Responses are faster when the figures in the pair are similar to the prime than when they are different from it. Manipulating prime exposure duration makes it possible to reveal early and late representations of the priming stimulus, thus probing the time course of its organization (e.g., Kimchi, 1998, 2000; Sekuler \& Palmer, 1992).

In the present study, we used the primed-matching paradigm to follow the microgenesis of groupings that varied in the processes involved in the grouping, with a focus on the processes of segregation and shape formation.

\section{EXPERIMENT 1}

We employed four organization conditions. In one condition, the priming stimuli were physically disconnected elements grouped into columns or rows by common lightness (Figure 1A). In a second condition, the priming stimuli were physically disconnected elements grouped into a triangle or an arrow by common lightness (Figure 1B). The grouping in these two conditions required the combining of elements together and their segregation from other elements on the basis of the same Gestalt principle of similarity: Elements similar to one another and different from other elements in lightness would group together and form larger units. These two conditions, however, might differ in complexity of shape formation: determination of vertical or horizontal orientation of the units in the first condition versus the formation of a distinctive shape in the second condition (Rock, 1986). In the third condition, homogeneous, physically disconnected elements grouped into a triangle or an arrow (Figure 1C). This grouping involved shape formation, but no segregation of some elements from other elements was required. In the fourth condition, the priming stimuli were a connected triangle or arrow line configuration (Figure 1D).

In each organization condition, the priming stimuli were presented at various durations, followed by a pair of test stimuli. The test stimuli were either similar to the grouped prime or dissimilar to it (see Figure 1). If grouping is achieved so that the grouped pattern of the prime is available for priming, responses to test pairs similar to the grouped prime would be expected to be faster than responses to test pairs that were dissimilar to the grouped prime. Priming effects observed under shorter and longer prime durations would suggest an earlier, rapid grouping versus a later or slower grouping.

If the time course of grouping depends on the processes involved in it, the different grouping conditions would vary in their time course, depending on whether they involved segregation, shape formation, or both. Thus, if segregation plays a crucial role in the time course of grouping, the two groupings by common lightness (into columns/rows and into triangle/arrow) would be slower than the other groupings. If shape formation is crucial, the groupings into a triangle or an arrow would be slower than grouping into columns/rows. If, however, the combination of segregation and shape formation is critical, grouping into a triangle or an arrow by common lightness would be slower than the other groupings.

\footnotetext{
Method

Participants. Forty-eight students at the University of Haifa, 37 women and 11 men (age, 19-29 years), participated in the experiment for course credit. The participants were randomly assigned to the four organization conditions, 12 participants in each condition. All the participants had normal or corrected-to-normal vision.

Apparatus. The experiment was controlled by an Indy Silicon Graphics workstation. The computer produced and displayed the stimuli, and the participants' reaction times (RTs) and correctness of responses were recorded by it. The participants rested their heads on a chinrest, so that their eyes were set to the height level of the center
} 


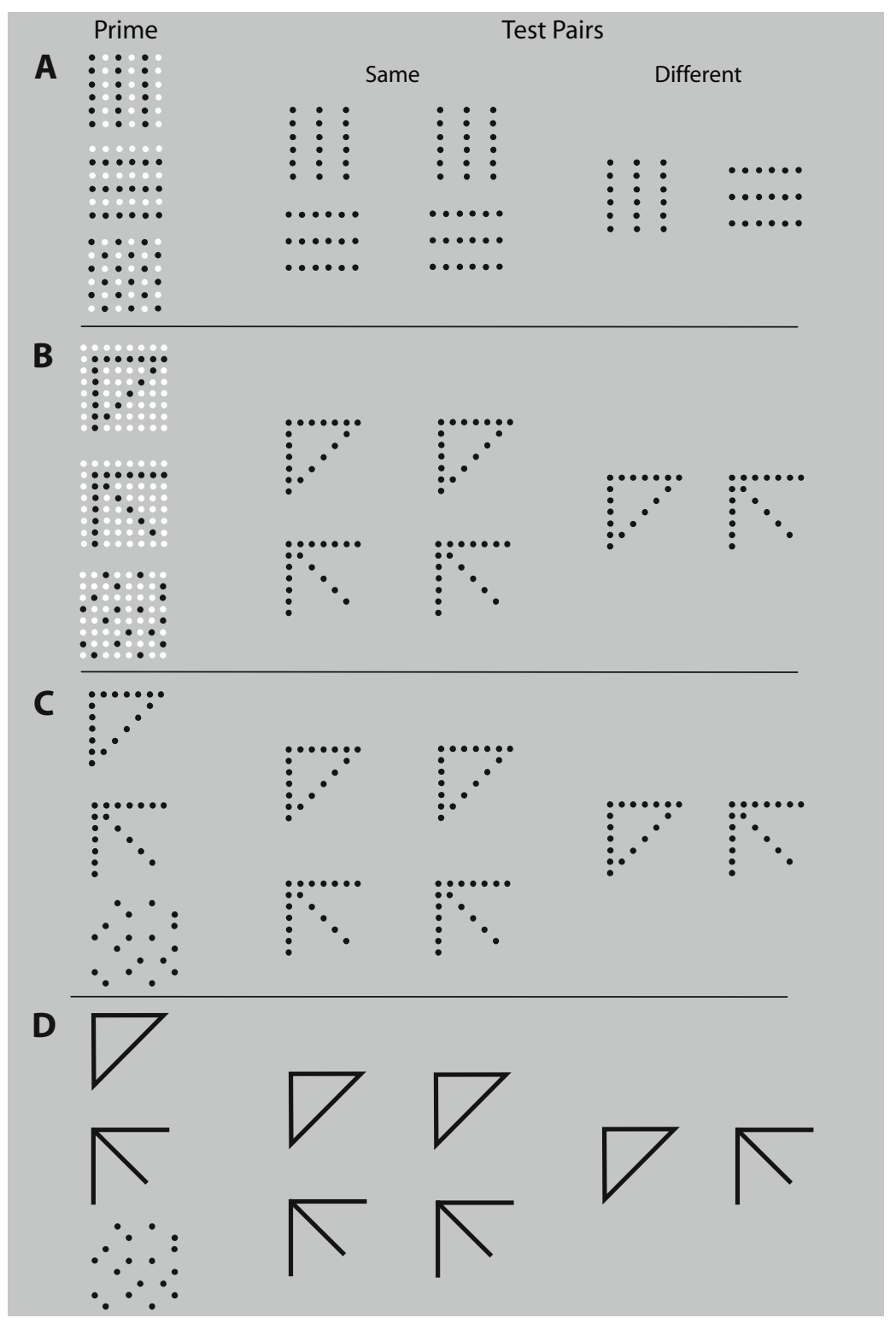

Figure 1. The priming stimuli and the same- and different-response test pairs used in each organization condition in Experiment 1. (A) Elements grouped into columns/ rows by common lightness. (B) Elements grouped into a triangle/arrow by common lightness. (C) Elements grouped into a triangle/arrow. (D) A connected line configuration of a triangle/arrow.

of the screen. They watched the screen through a circular aperture (14 $\mathrm{cm}$ in diameter) of a matte black cardboard sheet. The testing room was dimly lit.

Stimuli. Each trial included a priming stimulus followed by a test pair. The test stimuli consisted of two stimuli each. There were three types of similarity relations between the same-response test stimuli and the prime. In the similarity condition, the test stimuli were similar to the grouped prime (e.g., a triangle prime followed by a pair of triangles). In the dissimilarity condition, the test stimuli were dissimilar to the grouped prime (e.g., a triangle prime followed by a pair of arrows). In addition, a prime with an irrelevant or random arrangement was presented. In this case prime-test similarity was considered neutral (e.g., a random arrangement of elements followed by a pair of triangles) and served as a baseline condition.
All the stimuli were displayed on a gray screen. Viewing distance was $60 \mathrm{~cm}$. The distance between the centers of the stimuli in a test pair was $7.4^{\circ}$ of visual angle.

Columns/rows by common lightness (Figure 1A). The primes in this condition were elements grouped into columns by common lightness, elements grouped into rows by common lightness, and elements forming a checkerboard arrangement. Each priming stimulus included 36 equidistant solid circles, each $0.29^{\circ}$ in diameter, located in a $3.6^{\circ} \times 3.6^{\circ}$ square matrix. The distance between vertically or horizontally adjacent circles was $0.38^{\circ}$. Half of the circles were black, and the other half were white. There were two types of sameresponse test pairs: The column test pair included two 3-column stimuli, and the row test pair included two 3-row stimuli. Each column/row was made of six black circles. The size of the circles and 
the distance between vertically or horizontally adjacent circles were the same as those in the priming stimulus. The distances between columns or rows in the test stimuli were $1.1^{\circ}$. Different-response test pairs included a columns stimulus and a rows stimulus, with their position within a pair (right or left) counterbalanced across trials.

Triangle/arrow organization by common lightness (Figure 1B). The primes in this condition were elements grouped by common lightness into an isosceles triangle, elements grouped by common lightness into an arrow, and elements arranged randomly. Each priming stimulus included 64 equidistant solid circles, $0.29^{\circ}$ in diameter each, located in a $4.4^{\circ} \times 4.4^{\circ}$ square matrix. The distance between vertically or horizontally adjacent circles was $0.3^{\circ}$. Eighteen circles were black, and the rest were white. Each of the right angle sides of the triangle and the arrow subtended $3.83^{\circ}$. The same-response test pairs included two triangles or two arrows, each of which was made of 18 black circles. The size of the circles and the distances between adjacent circles were identical to those for the corresponding shapes in the priming stimuli. Different-response test pairs included a triangle and an arrow, with their position within a pair counterbalanced across trials.

Triangle/arrow (Figure 1C). Each of the priming stimuli included 18 black circles, grouped into a triangle or an arrow or randomly arranged. The test pairs and the sizes and distances of the black circles in the primes were the same as those in the previous condition.

Connected triangle/arrow (Figure 1D). The priming stimuli and the test pairs included black lines $\left(0.19^{\circ}\right.$ in width $)$ that formed a connected triangle or arrow of the same global sizes as those in the previous condition. The neutral prime was identical to the one in the previous condition.

Design. The experiment consisted of the factorial combination of five factors in a mixed design. Organization condition (columns/ rows by common lightness, triangle/arrow by common lightness, triangle/arrow, and connected triangle/arrow) was administered between subjects. The other four variables were administered within subjects: priming stimulus (columns, rows, or a checkerboard arrangement in the columns/rows condition; triangle, arrow, or a random arrangement in the other conditions; see the prime in Figure 1), prime duration $(40,90,190,390$, or $690 \mathrm{msec}$ ), test pair (a column pair or a row pair in the columns/rows condition; a triangle pair or an arrow pair in the other conditions; see the same test pairs in Figure 1), and response (same or different). All combinations of the latter four factors were randomized within blocks, with each combination occurring on an equal number of trials. The combination of priming stimulus and test pair produced three types of similarity relations between the same-response test pairs and the prime: similarity, dissimilarity, and neutral. Each test pair was similar to one grouped prime and dissimilar to the other. For example, in the columns/rows condition, a similarity relation comprises a column prime followed by a same-response column test pair and a row prime followed by a same-response row test pair; a dissimilarity relation comprises a column prime followed by a same-response row test pair and a row prime followed by a same-response column test pair; a neutral relation comprises a control prime followed by each of the test pairs. For each organization condition, there were four blocks of 240 trials each, preceded by a 24 -trial practice block. Each experimental block was divided into two halves for the subjects' convenience.

Procedure. Each trial started with a central fixation cross that appeared for $250 \mathrm{msec}$, followed by a 250 -msec blank screen. Then one of the priming stimuli appeared in the center for 40, 90, 190, 390 , or $690 \mathrm{msec}$. Immediately thereafter, a test pair was displayed until response, or for a maximum of $3,000 \mathrm{msec}$. At this point, the participant had to decide as quickly and as accurately as possible whether the two stimuli in the test pair were the same as each other or different from one another. RT was measured from the onset of the test pair until a response key was pressed. An auditory tone provided feedback for incorrect responses or no responses. These trials were retaken at the end of the block. The intertrial interval was $1,000 \mathrm{msec}$. Figure 2 presents the sequence of events in a trial.

\section{Results}

All RT summaries and analyses are based on participants' median RTs for correct same responses. RTs outside the range of 250-2,500 msec were omitted from the analyses $(0.2 \%$ of all the trials). Mean correct RT and error rate (ER) are presented in Table 1 as a function of prime-test similarity and prime duration for the four organization conditions. The participants were highly accurate (mean ER $=2.5 \%$ ), and no indications of a speed-accuracy trade-off were found.

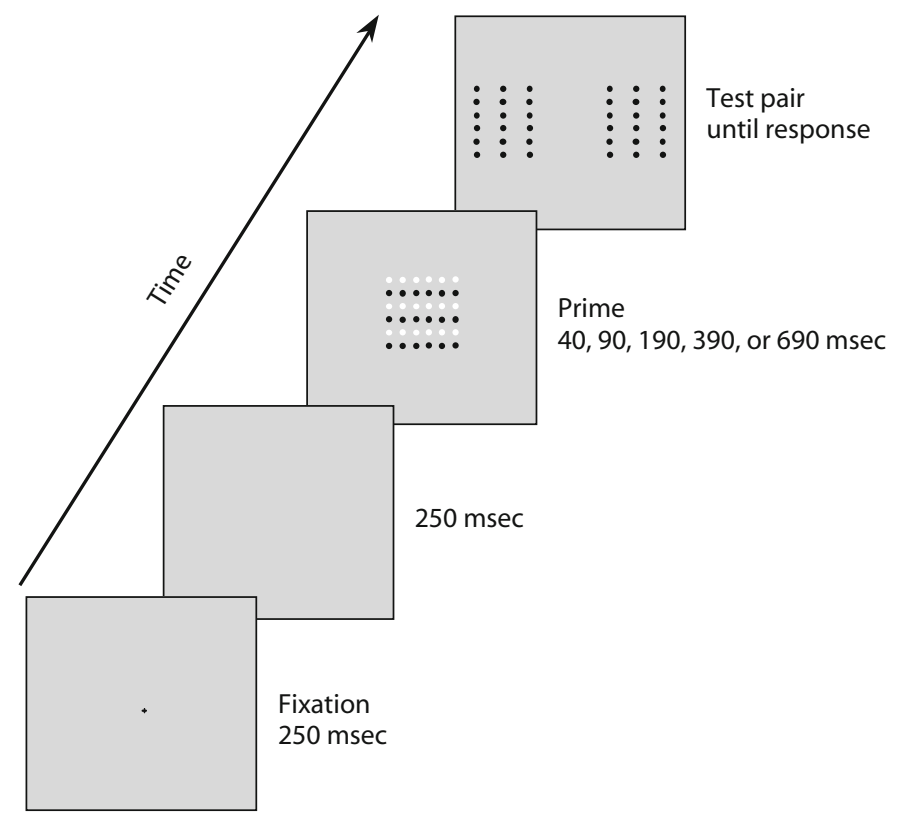

Figure 2. Sequence of events in an experimental trial. The illustration depicts a prime-test dissimilarity trial in the columns/rows condition. 
Table 1

Mean Correct Reaction Times (in Milliseconds) and Error Rates (in \%, in Parentheses) As a Function of Prime-Test Similarity and Prime Duration (in Milliseconds) for the Four Types of Organization in Experiment 1

\begin{tabular}{|c|c|c|c|c|c|c|c|c|c|c|c|c|c|c|c|}
\hline \multirow[b]{3}{*}{ Type of Organization } & \multicolumn{15}{|c|}{ Prime Duration } \\
\hline & \multicolumn{3}{|c|}{40} & \multicolumn{3}{|c|}{90} & \multicolumn{3}{|c|}{190} & \multicolumn{3}{|c|}{390} & \multicolumn{3}{|c|}{690} \\
\hline & SIM & DIS & $\mathrm{N}$ & SIM & DIS & $\mathrm{N}$ & SIM & DIS & $\mathrm{N}$ & SIM & DIS & $\mathrm{N}$ & SIM & DIS & $\mathrm{N}$ \\
\hline $\begin{array}{l}\text { Columns/rows by common } \\
\text { lightness }\end{array}$ & $\begin{array}{c}582 \\
(1.0)\end{array}$ & $\begin{array}{c}600 \\
(2.2)\end{array}$ & $\begin{array}{l}578 \\
(2.0)\end{array}$ & $\begin{array}{l}576 \\
(0.7)\end{array}$ & $\begin{array}{l}591 \\
(2.7)\end{array}$ & $\begin{array}{c}591 \\
(1.7)\end{array}$ & $\begin{array}{c}577 \\
(1.5)\end{array}$ & $\begin{array}{c}610 \\
(2.2)\end{array}$ & $\begin{array}{c}582 \\
(1.8)\end{array}$ & $\begin{array}{c}579 \\
(1.0)\end{array}$ & $\begin{array}{c}603 \\
(2.7)\end{array}$ & $\begin{array}{c}596 \\
(1.2)\end{array}$ & $\begin{array}{c}549 \\
(1.3)\end{array}$ & $\begin{array}{c}585 \\
(1.3)\end{array}$ & $\begin{array}{c}562 \\
(1.5)\end{array}$ \\
\hline $\begin{array}{l}\text { Triangle/arrow by common } \\
\text { lightness }\end{array}$ & $\begin{array}{c}644 \\
(0.8)\end{array}$ & $\begin{array}{c}635 \\
(0.8)\end{array}$ & $\begin{array}{c}635 \\
(0.8)\end{array}$ & $\begin{array}{c}618 \\
(1.3)\end{array}$ & $\begin{array}{c}642 \\
(1.5)\end{array}$ & $\begin{array}{c}630 \\
(1.0)\end{array}$ & $\begin{array}{l}635 \\
(2.7)\end{array}$ & $\begin{array}{c}627 \\
(1.5)\end{array}$ & $\begin{array}{c}627 \\
(0.8)\end{array}$ & $\begin{array}{c}618 \\
(1.0)\end{array}$ & $\begin{array}{c}662 \\
(0.7)\end{array}$ & $\begin{array}{l}638 \\
(2.2)\end{array}$ & $\begin{array}{c}591 \\
(1.3)\end{array}$ & $\begin{array}{l}638 \\
(2.2)\end{array}$ & $\begin{array}{l}621 \\
(0.8)\end{array}$ \\
\hline $\begin{array}{l}\text { Triangle/arrow with no } \\
\text { segregation }\end{array}$ & $\begin{array}{c}605 \\
(1.3)\end{array}$ & $\begin{array}{c}641 \\
(5.7)\end{array}$ & $\begin{array}{c}637 \\
(5.0)\end{array}$ & $\begin{array}{c}616 \\
(1.9)\end{array}$ & $\begin{array}{c}633 \\
(4.3)\end{array}$ & $\begin{array}{l}621 \\
(2.7)\end{array}$ & $\begin{array}{c}611 \\
(1.8)\end{array}$ & $\begin{array}{c}636 \\
(2.2)\end{array}$ & $\begin{array}{c}631 \\
(4.8)\end{array}$ & $\begin{array}{c}602 \\
(1.5)\end{array}$ & $\begin{array}{r}672 \\
(6.5)\end{array}$ & $\begin{array}{c}638 \\
(3.2)\end{array}$ & $\begin{array}{l}584 \\
(2.9)\end{array}$ & $\begin{array}{c}673 \\
(8.8)\end{array}$ & $\begin{array}{c}613 \\
(1.0)\end{array}$ \\
\hline Connected triangle/arrow & $\begin{array}{c}548 \\
(1.2)\end{array}$ & $\begin{array}{c}589 \\
(5.2)\end{array}$ & $\begin{array}{l}552 \\
(2.2)\end{array}$ & $\begin{array}{c}559 \\
(3.6)\end{array}$ & $\begin{array}{l}590 \\
(3.9)\end{array}$ & $\begin{array}{c}570 \\
(3.5)\end{array}$ & $\begin{array}{c}552 \\
(2.9)\end{array}$ & $\begin{array}{c}603 \\
(5.4)\end{array}$ & $\begin{array}{l}570 \\
(2.1)\end{array}$ & $\begin{array}{c}531 \\
(0.8)\end{array}$ & $\begin{array}{c}620 \\
(6.9)\end{array}$ & $\begin{array}{l}565 \\
(2.2)\end{array}$ & $\begin{array}{l}519 \\
(2.4)\end{array}$ & $\begin{array}{c}604 \\
(7.4)\end{array}$ & $\begin{array}{l}540 \\
(1.5)\end{array}$ \\
\hline
\end{tabular}

Note-SIM, similarity; DIS, dissimilarity; N, neutral.

Priming indicates how much the prime speeded up same responses to a test pair similar to the prime versus a test pair dissimilar to the prime. The amount of priming is defined by the difference between RT to a dissimilar test pair versus a similar test pair minus the baseline RT difference to these test pairs in the neutral condition. Since in our experiment, each of the two test pairs (in each organization condition) was similar to one grouped prime and dissimilar to the other grouped prime, the difference in RT between the two critical prime-test similarity conditions - similarity and dissimilarity, collapsed across the two grouped primes - provides a valid measure of priming that takes into account any baseline response differences between specific test pairs. Priming effects in RT are plotted by lines in Figure 3 as a function of prime duration for each type of organization. We also computed priming effects in ER, defined as the difference in ER between the dissimilarity and the similarity conditions. Priming ER effects are depicted by the bars in Figure 3 as a function of prime duration for each organization condition.

The collapsed RT data were submitted to an ANOVA that treated type of organization as a between-subjects factor and prime-test similarity (similarity vs. dissimilarity) and prime duration as within-subjects factors. A significant three-way interaction among these factors was found $\left[F(12,176)=2.28, M S_{\mathrm{e}}=613, p<.01\right]$, indicating that the priming depended both on prime duration and on type of organization. Planned specific comparisons were performed to determine priming effects as a function of prime duration for each type of organization.

Columns/rows by common lightness. Responses to the test pair similar to the grouped prime were significantly faster (by an average of $26 \mathrm{msec}$ ) than were responses to the test pair dissimilar to the prime $[F(1,11)=$ 55.27, $\left.M S_{\mathrm{e}}=351, p<.0001\right]$. Priming effect did not vary significantly with time $\left[F(4,44)=1.41, M S_{\mathrm{e}}=385\right.$, $p>.25]$. Significant priming was observed at the shortest prime duration of $40 \mathrm{msec}\left[F(1,11)=11.35, M S_{\mathrm{e}}=\right.$ $180, p<.007]$, and was also noticed at prime durations of $190 \mathrm{msec}$ and longer $(p<.05)$. Figure 3A shows the steady priming effects throughout the time course.

Triangle/arrow by common lightness. There was a significant priming effect $\left[F(1,11)=29.28, M S_{\mathrm{e}}=398\right.$, $p<.0003]$, which interacted significantly with prime duration $\left[F(4,44)=8.87, M S_{\mathrm{e}}=501, p<.0002\right]$. No priming was observed at prime durations of 40 and $190 \mathrm{msec}$, $(F \mathrm{~s}<1)$. Significant priming effects were noticed consistently only at the longer prime duration of $390 \mathrm{msec}$ (average, $44 \mathrm{msec}$ ) and $690 \mathrm{msec}$ (average, $48 \mathrm{msec}$ ) $\left[F(1,11)=32.35, M S_{\mathrm{e}}=370, p<.0002 ; F(1,11)=\right.$ $18.21, M S_{\mathrm{e}}=733, p<.002$, respectively]. These relatively late priming effects can be seen in Figure 3B.

Triangle/arrow. There was a significant effect of priming $\left[F(1,11)=55.11, M S_{\mathrm{e}}=1,230, p<.0001\right]$ that interacted significantly with prime duration $[F(4,44)=$ $\left.5.68, M S_{\mathrm{e}}=983, p<.0009\right]$. Significant priming effects were observed at the shortest prime duration of $40 \mathrm{msec}$ $\left[F(1,11)=7.52, M S_{\mathrm{e}}=1,060, p<.02\right]$ and were steadily noticed at durations of $190 \mathrm{msec}$ and longer $(p<.04)$. As can be seen in Figure 3C, the amount of priming increased with time: Whereas a $36-\mathrm{msec}$ priming was found at the 40-msec duration, an 89-msec effect was at the $690-\mathrm{msec}$ duration.

Connected triangle/arrow. There was a significant effect of priming $\left[F(1,11)=83, M S_{\mathrm{e}}=1,274, p<\right.$ $.0001]$, which interacted significantly with prime duration $\left[F(4,44)=7.08, M S_{\mathrm{e}}=582, p<.0002\right]$. Significant priming effects were found at the shortest prime duration of $40 \mathrm{msec}\left[F(1,11)=11.64, M S_{\mathrm{e}}=861, p<.006\right]$ and throughout the prime durations $(p<.05)$. Figure 3D shows the increase in the amount of priming with time: from $41 \mathrm{msec}$ at the $40-\mathrm{msec}$ duration to $85 \mathrm{msec}$ at the 690-msec duration.

The ER data showed a similar pattern of results (see Figure 3, bars), but not all the effects were statistically significant. The ER data were submitted to a mixed design ANOVA (type of organization $\times$ prime-test similarity $\times$ prime duration). The triple interaction was not significant $\left[F(12,176)=1.56, M S_{\mathrm{e}}=0.08, p>.1\right]$, but priming effects differed among types of organization $[F(3,44)=$ $\left.6.68, M S_{\mathrm{e}}=0.15, p<.0008\right]$. Significant priming effects were found for columns/rows by common lightness [Figure 3A; $\left.F(1,11)=5.47, M S_{\mathrm{e}}=0.07, p<.04\right]$, for triangle/arrow [Figure 3C; $F(1,11)=48.11, M S_{\mathrm{e}}=0.08, p<$ .0001 ], and for the connected triangle/arrow [Figure 3D; $\left.F(1,11)=9.84, M S_{\mathrm{e}}=0.0039, p<.01\right]$. No significant 
A

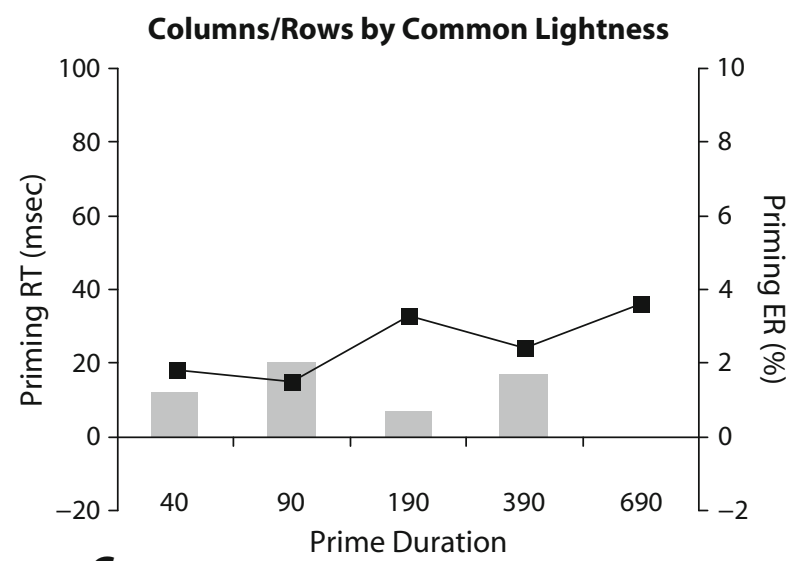

C

Triangle/Arrow With No Segregation

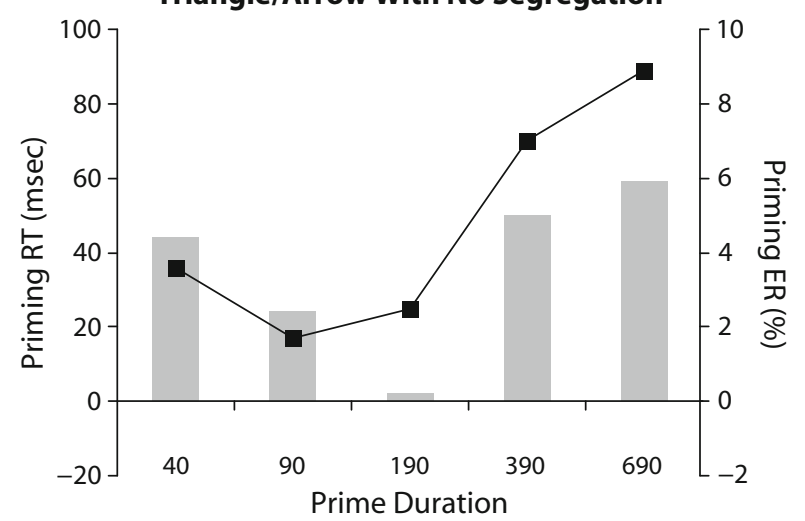

B

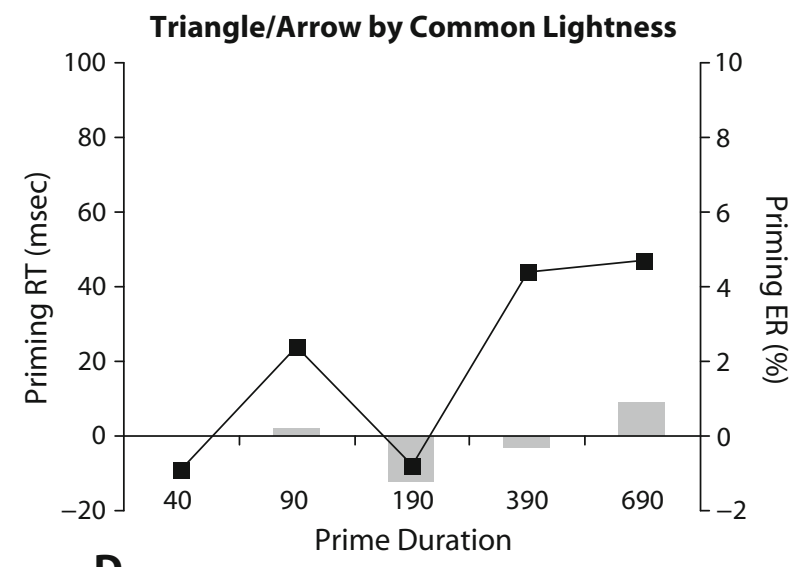

D

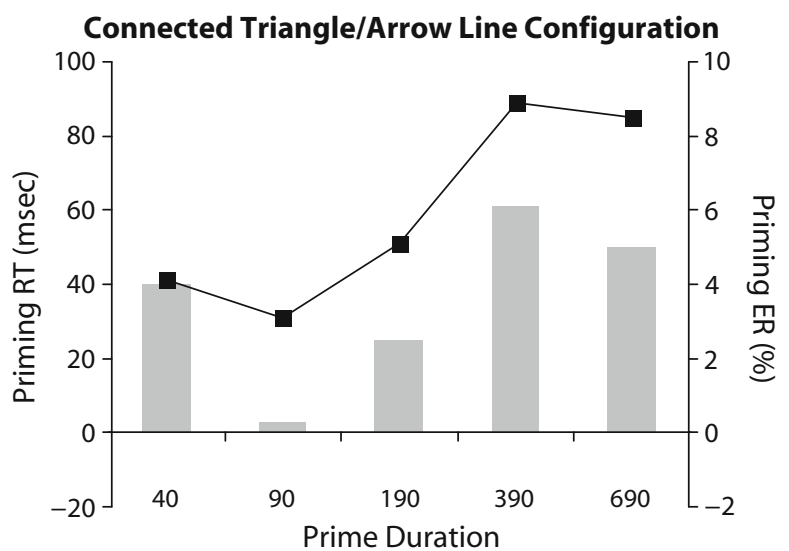

Figure 3. Priming effects as a function of prime duration for the four types of organization in Experiment 1. The lines depict priming response times (RTs), and the bars depict priming error rates (ERs) (see the text for details).

priming was found for the triangle/arrow by common lightness (Figure 3B; $F<1$ ).

\section{Discussion}

The results of this experiment clearly show that the different groupings varied in their time course. The triangle/ arrow grouped by common lightness was available for priming at relatively long exposure durations, indicating slow or late grouping. On the other hand, the columns/ rows grouped by common lightness, the triangle/arrow with no segregation, and the connected triangle/arrow were available for priming at the shortest exposure duration of $40 \mathrm{msec}$, indicating an early, rapid grouping.

These results suggest that the time course of grouping depends on the processes involved in the grouping. Grouping into columns/rows that involved segregation was achieved early and rapidly. Grouping into a shape, however, was accomplished early and rapidly when no segregation of some elements from other elements was involved, as in the triangle/arrow and the connected triangle/ arrow conditions. One may argue that the priming effects observed in these conditions have resulted from representing just the oblique lines and, thus, may not indicate formation of the global shape. Yet this account does not agree with the configural superiority effect (Pomerantz, Sager, \& Stoever, 1977), according to which discriminating the orientation of oblique lines demands more time when they appear separately than when they appear in a configural context (i.e., triangle and arrow). Thus, the priming effects observed for the triangle/arrow patterns are more likely to result from a prime-test representational similarity of the whole configuration than from similarity in the oblique lines. The enhancement of priming with prolonged exposures in these conditions suggests that although the grouping into the global shape occurred relatively early, the percept still continued to evolve. This implies a consolidation of the shape representation with time.

Of particular interest is the difference between the results for the columns/rows by common lightness and the triangle/arrow by common lightness. Although these two groupings were guided by the same grouping principle of similarity in lightness, they nevertheless had different time courses: Priming was evident at the brief prime duration in the columns/rows condition, but it emerged at longer duration in the triangle/arrow condition. This was further confirmed by comparing priming effects over the brief prime duration range $(40-190 \mathrm{msec})$ between these conditions. The analysis showed a significant interaction be- 
tween type of organization and priming $[F(1,22)=8.62$, $\left.M S_{\mathrm{e}}=412, p<.008\right]$. At this duration range, a significant priming effect was found for columns/rows $[F(1,11)=$ $\left.31, M S_{\mathrm{e}}=284, p<.0002\right]$, but not for triangle/arrow $(F<1)$. Shape formation per se-forming a shape (a triangle or an arrow) versus forming lines (columns or rows) - cannot account for this difference, because our results showed that elements were grouped into a triangle or an arrow rapidly and early when no segregation from other elements was involved. Rather, it is grouping that required both segregation and shape formation that consumed time. Presumably, in this case, there was a need to determine which group should be designated as figure and which as ground. In the columns/rows condition, the grouping by common lightness results in an equal number of black and white lines (vertical or horizontal), all of which are perceived as "figures" on a gray background. The grouping into a shape (a triangle or an arrow) by common lightness, on the other hand, requires designating the group of black elements as a figure and the group of white elements as ground. Determinants of figure-ground differentiation include size, surroundedness, symmetry, convexity, orientation, contrast, and familiarity (e.g., Koffka, 1935; Peterson, 2003; Rock, 1986; Rubin, 1921). Although the black group in the triangle/arrow display is likely to be favored as figure because of its smaller size and, perhaps, surroundedness, conflicting determinants of figure-ground differentiation (e.g., symmetry and convexity) may be at work as well, resulting in a need to resolve figure-ground relations among segregated units. Thus, when segregation was involved, grouping that did not require resolving figure-ground relations (as in columns/rows grouped by common lightness) was accomplished rapidly, but grouping into a shape that required figure-ground resolution (as in grouping into triangle/arrow by common lightness) consumed time.

In the next experiment, we further examined the time course of grouping as a function of the processes of segregation and figure-ground resolution with a different set of shapes-squares and crosses. This allowed us to test the effect of shape goodness on the time course of grouping.

\section{EXPERIMENT 2}

Three organization conditions were employed in this experiment. In one condition, the priming stimuli were physically disconnected elements grouped into a square or a cross by common lightness. In the second condition, the priming stimuli were physically disconnected elements grouped into a square/cross, but no segregation from other elements was required. In the third condition, four line segments grouped into a square/cross, and no segregation was involved. The first two conditions corresponded to the two triangle/arrow conditions in Experiment 1. The third condition involved line configurations like those in the connected triangle/arrow condition in Experiment 1, except that in the present experiment, the line segments were disconnected.
We examined whether the time course of grouping elements into a square/cross would be similar to that of grouping elements into a triangle/arrow. A clear distinction of pattern goodness exists between these two types of shapes, based on the number of symmetries exhibited by the shape (Feldman, 2000; Garner, 1974; Palmer, 1991). A square or a cross that has bilateral symmetry about vertical, horizontal, and diagonal axes is considered to be a "better" shape than is the isosceles triangle and arrow used in Experiment 1, which have only one axis of symmetry.

\section{Method}

Participants. Thirty-eight students, 19 women and 19 men (age, 18-29 years), participated in this experiment for course credit: 14 students in the square/cross by common lightness condition, 12 in the square/cross condition, and 12 in the disconnected square/ cross line configuration condition. All the participants had normal or corrected-to-normal vision, and none of them had taken part in Experiment 1.

Stimuli. In the square/cross organization by common lightness condition (Figure $4 \mathrm{~A}$ ), the priming stimuli included 81 equidistant solid circles, located in a $5^{\circ} \times 5^{\circ}$ square matrix. The diameter of a circle subtended $0.29^{\circ}$, and the vertical or horizontal distance between adjacent circles subtended $0.3^{\circ}$. In one priming stimulus, the circles (13 black and 68 white) grouped by common lightness into a cross with each side subtending $3.83^{\circ}$. In the other prime, the circles (16 black and 65 white) grouped by common lightness into a square with each side subtending $2.65^{\circ}$, and in the third prime, 15 black and 66 white circles formed a random arrangement. One same-response test pair included two crosses, each of which was made of 13 black circles, and the other test pair included two squares, each made of 16 black circles. The size of each test figure was identical to that of the corresponding shape in the prime.

In the square/cross condition (Figure 4B), priming stimuli grouped into a cross or a square or formed a neutral organization. These stimuli were made of 13,16 , or 15 black circles, respectively. The same cross and square organizations were used in the test pairs.

In the disconnected square/cross condition (Figure 4C), four line segments, each $1.47^{\circ}$ in length, were grouped into a priming stimulus of a square or a cross. The neutral prime was identical to the one in the previous condition. Test pairs included black lines that formed a connected square or cross of the same global size as that in the previous condition.

The apparatus, design, procedure, and any other aspect of the stimuli were the same as those in Experiment 1.

\section{Results}

RT summaries and analyses are based on the participants' median RTs for correct same responses, after omitting $0.3 \%$ of all the trials on which RTs were outside the range of 250-2,500 msec. Mean correct RTs and ERs, collapsed across the two grouped primes, are presented in Table 2 as a function of prime-test similarity and prime duration for the three organization conditions. The participants were highly accurate (mean ER $=1.7 \%$ ), and no indications of a speed-accuracy trade-off were found. Priming effects, defined as the difference in RT (or ER) between the primetest similarity versus dissimilarity conditions, are depicted in Figure 5 (lines for RT and bars for ER) as a function of prime duration for each type of organization.

Planned comparisons were carried out on the RT data to examine the RT priming effects as a function of prime duration for each type of organization. Specifically, we 


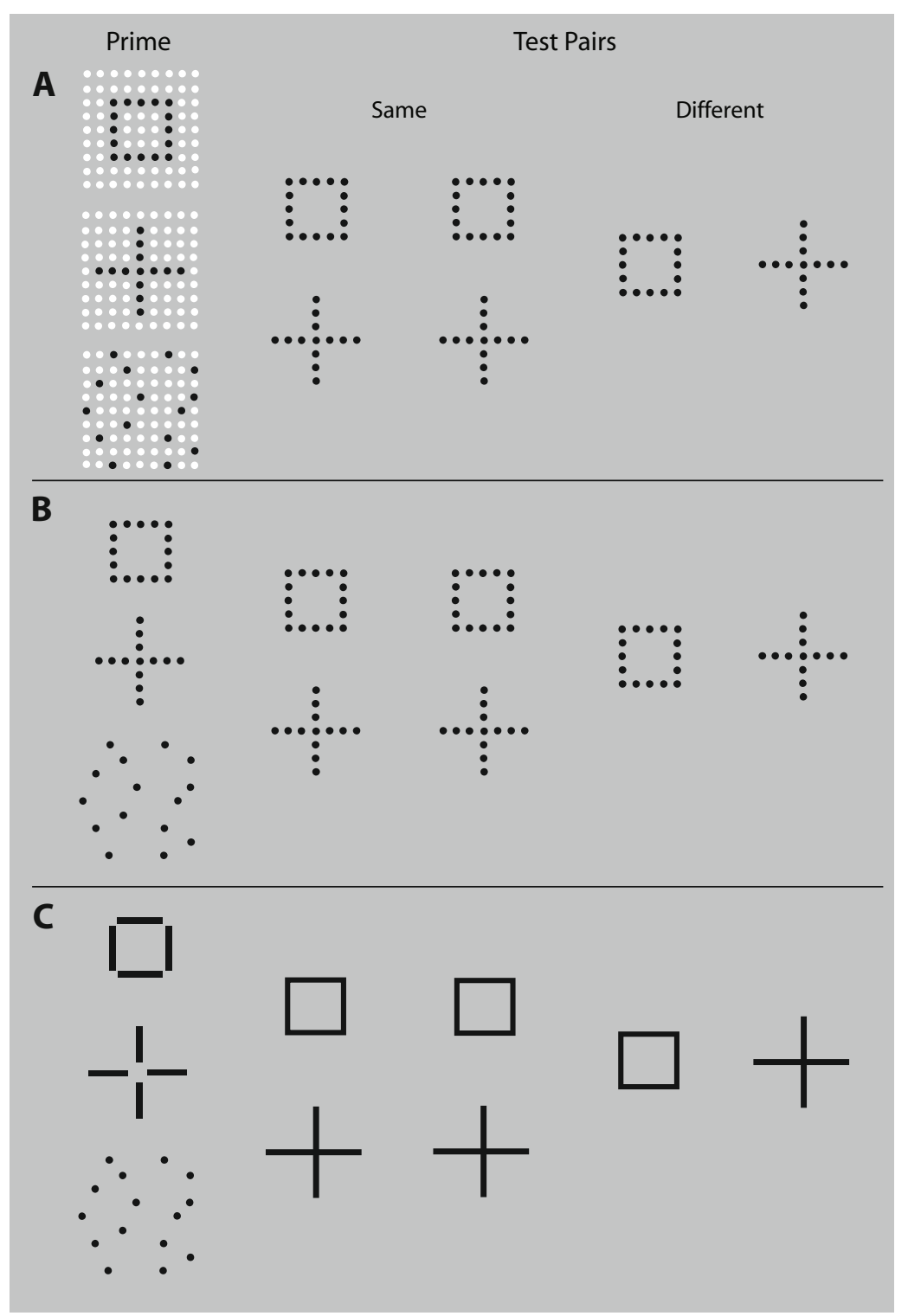

Figure 4. The priming stimuli and the same- and different-response test pairs used in each organization condition in Experiment 2. (A) Elements grouped into a square/ cross by common lightness. (B) Elements grouped into a square/cross. (C) A disconnected line configuration of a square/cross.

examined whether priming effects were evident under the earliest prime duration of $40 \mathrm{msec}$ and from which point in time the priming effects were steadily observed.

Square/cross by common lightness. There was a significant priming effect $\left[F(1,13)=15.52, M S_{\mathrm{e}}=1,028\right.$, $p<.002$ ], which did not interact significantly with prime duration $\left[F(4,52)=1.39, M S_{\mathrm{e}}=744, p>.25\right]$. As can be seen in Figure 5A, the values observed under the short durations of 40,90, and $190 \mathrm{msec}$ were small (average, 15,11 , and $11 \mathrm{msec}$, respectively), and none reached statistical significance $\left[F(1,13)=1.24, M S_{\mathrm{e}}=1,250, p>\right.$ $.28 ; F(1,13)=2.34, M S_{\mathrm{e}}=388, p>.15 ; F(1,13)=$ $2.48, M S_{\mathrm{e}}=366, p>.13$, respectively]. Significant priming was consistently noticed only at $390 \mathrm{msec}$ (average,
$33 \mathrm{msec}$ ) and $690 \mathrm{msec}$ (average, $35 \mathrm{msec})[F(1,13)=$ $10.66, M S_{\mathrm{e}}=729, p<.007 ; F(1,13)=7.04, M S_{\mathrm{e}}=$ $1,271, p<.02$, respectively].

Square/cross. There was a significant priming effect [average, $55 \mathrm{msec} ; F(1,11)=110.48, M S_{\mathrm{e}}=841$, $p<.0001]$, which did not interact with prime duration $(F<1)$. Significant priming effects were observed at the earliest duration of $40 \mathrm{msec}\left[F(1,11)=40.06, M S_{\mathrm{e}}=\right.$ $402, p<.0001]$ and at all the longer durations $(p<$ .0006 ). Figure 5B shows the stability of these priming effects during time.

Disconnected square/cross. There was a significant priming effect [average, $47 \mathrm{msec} ; F(1,11)=94.85, M S_{\mathrm{e}}=$ $698, p<.0001]$ which did not interact with prime dura- 
Table 2

Mean Correct Reaction Times (in Milliseconds) and Error Rates (in \%, in Parentheses) As a Function of Prime-Test Similarity and Prime Duration (in Milliseconds) for the Three Types of Organization in Experiment 2

\begin{tabular}{|c|c|c|c|c|c|c|c|c|c|c|c|c|c|c|c|}
\hline \multirow[b]{3}{*}{ Type of Organization } & \multicolumn{15}{|c|}{ Prime Duration } \\
\hline & \multicolumn{3}{|c|}{40} & \multicolumn{3}{|c|}{90} & \multicolumn{3}{|c|}{190} & \multicolumn{3}{|c|}{390} & \multicolumn{3}{|c|}{690} \\
\hline & SIM & DIS & $\mathrm{N}$ & SIM & DIS & $\mathrm{N}$ & SIM & DIS & $\mathrm{N}$ & SIM & DIS & $\mathrm{N}$ & SIM & DIS & $\mathrm{N}$ \\
\hline $\begin{array}{l}\text { Square/cross by common } \\
\text { lightness }\end{array}$ & $\begin{array}{l}569 \\
(0.9)\end{array}$ & $\begin{array}{c}584 \\
(1.7)\end{array}$ & $\begin{array}{c}576 \\
(1.7)\end{array}$ & $\begin{array}{l}565 \\
(1.7)\end{array}$ & $\begin{array}{c}577 \\
(1.6)\end{array}$ & $\begin{array}{c}563 \\
(1.3)\end{array}$ & $\begin{array}{l}576 \\
(1.1)\end{array}$ & $\begin{array}{l}587 \\
(0.4)\end{array}$ & $\begin{array}{c}560 \\
(1.1)\end{array}$ & $\begin{array}{l}546 \\
(0.7)\end{array}$ & $\begin{array}{l}579 \\
(1.7)\end{array}$ & $\begin{array}{l}565 \\
(2.3)\end{array}$ & $\begin{array}{l}525 \\
(1.5)\end{array}$ & $\begin{array}{l}560 \\
(2.2)\end{array}$ & $\begin{array}{l}549 \\
(0.9)\end{array}$ \\
\hline $\begin{array}{l}\text { Square/cross with no } \\
\text { segregation }\end{array}$ & $\begin{array}{c}546 \\
(1.5)\end{array}$ & $\begin{array}{l}597 \\
(4.2)\end{array}$ & $\begin{array}{c}544 \\
(1.0)\end{array}$ & $\begin{array}{c}540 \\
(1.0)\end{array}$ & $\begin{array}{l}590 \\
(2.4)\end{array}$ & $\begin{array}{c}544 \\
(1.0)\end{array}$ & $\begin{array}{l}539 \\
(1.4)\end{array}$ & $\begin{array}{l}588 \\
(3.7)\end{array}$ & $\begin{array}{c}544 \\
(1.5)\end{array}$ & $\begin{array}{l}518 \\
(1.5)\end{array}$ & $\begin{array}{l}581 \\
(3.8)\end{array}$ & $\begin{array}{l}556 \\
(1.2)\end{array}$ & $\begin{array}{l}505 \\
(1.2)\end{array}$ & $\begin{array}{l}570 \\
(5.0)\end{array}$ & $\begin{array}{l}535 \\
(1.2)\end{array}$ \\
\hline Disconnected square/cross & $\begin{array}{c}554 \\
(1.5)\end{array}$ & $\begin{array}{l}593 \\
(4.2)\end{array}$ & $\begin{array}{c}569 \\
(1.7)\end{array}$ & $\begin{array}{c}555 \\
(1.5)\end{array}$ & $\begin{array}{c}588 \\
(1.8)\end{array}$ & $\begin{array}{c}553 \\
(1.5)\end{array}$ & $\begin{array}{c}558 \\
(0.5)\end{array}$ & $\begin{array}{c}605 \\
(1.7)\end{array}$ & $\begin{array}{c}565 \\
(0.5)\end{array}$ & $\begin{array}{c}531 \\
(0.8)\end{array}$ & $\begin{array}{c}595 \\
(3.4)\end{array}$ & $\begin{array}{c}561 \\
(1.0)\end{array}$ & $\begin{array}{c}508 \\
(1.5)\end{array}$ & $\begin{array}{c}558 \\
(1.7)\end{array}$ & $\begin{array}{c}534 \\
(0.5) \\
\end{array}$ \\
\hline
\end{tabular}

Note-SIM, similarity; DIS, dissimilarity; N, neutral.

tion $\left[F(4,44)=1.18, M S_{\mathrm{e}}=650, p>.33\right]$. Significant priming effects were found at $40 \mathrm{msec}[F(1,11)=12.78$, $\left.M S_{\mathrm{e}}=727, p<.005\right]$, as well as at the longer durations $(p<.005)$. The consistency of the priming effects during time can be observed in Figure 5C.

The pattern of results observed for the ER data was similar (see Figure 5, bars), but not all the effects were statistically significant. Significant priming effects were found for the square/cross $\left[F(1,13)=8.79, M S_{\mathrm{e}}=0.22\right.$, $p<.02 ;$ Figure $5 \mathrm{~B}]$ and for the disconnected square/cross
$\left[F(1,13)=9.23, M S_{\mathrm{e}}=0.07, p<.02\right.$; Figure $\left.5 \mathrm{C}\right]$, but not for the square/cross by common lightness $[F(1,13)=$ $1.04, M S_{\mathrm{e}}=0.05, p>.32$; Figure 5A].

\section{Discussion}

The results concerning the onset of the priming effects converged nicely with the results for the corresponding conditions in Experiment 1. The square/cross grouped by common lightness, like the triangle/arrow grouped by common lightness, was available for priming relatively
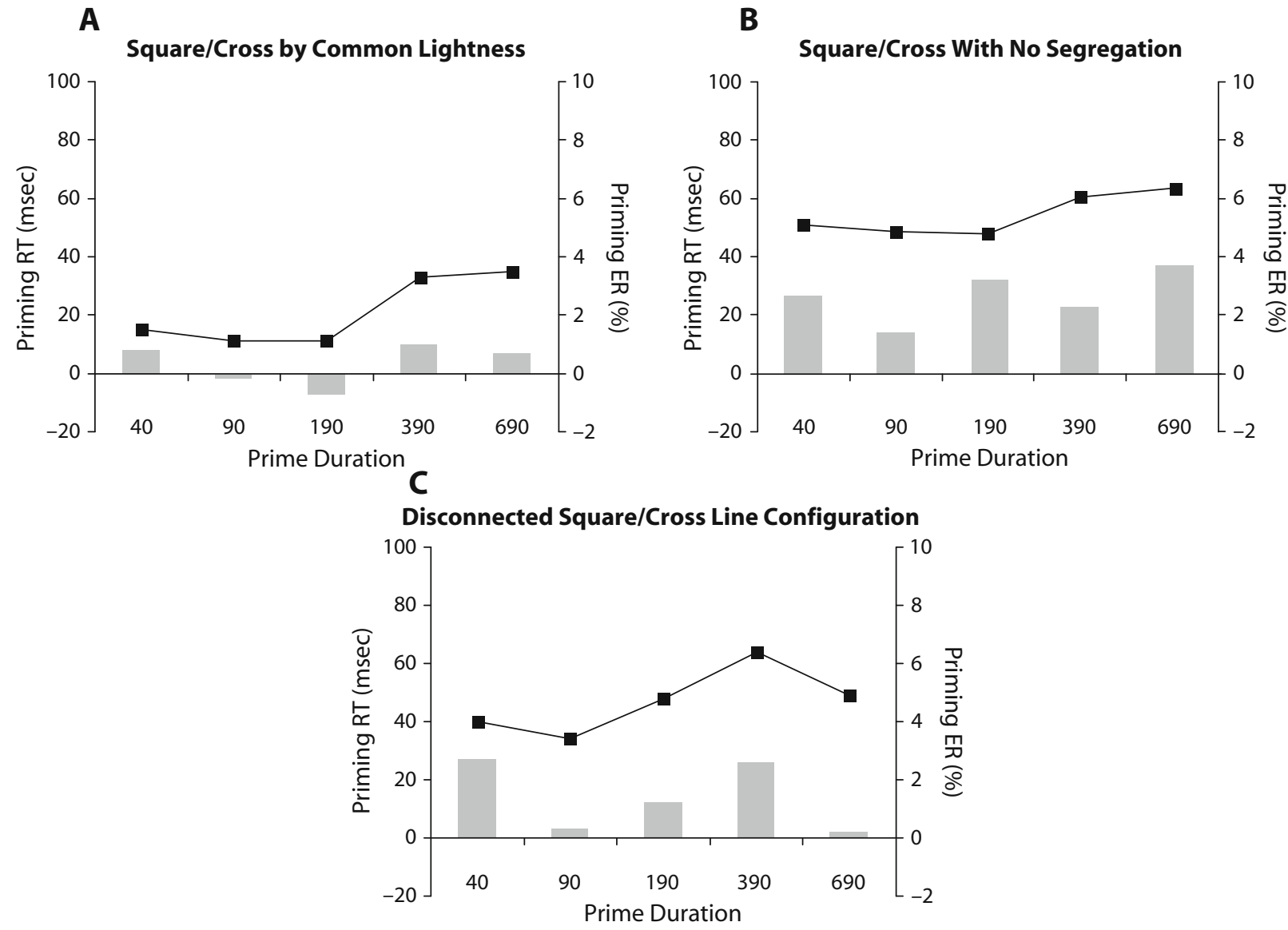

Figure 5. Priming effects as a function of prime duration for the three types of organization in Experiment 2. The lines depict priming response times (RTs) and the bars depict priming error rates (ERs). 
late in time, indicating slow grouping. The convergence of the results for these two types of shapes grouped by common lightness was further confirmed in an analysis that compared these two shape conditions, which indicated that priming varied significantly with prime duration $\left[F(4,96)=6.97, M S_{\mathrm{e}}=632, p<.001\right]$ but that the interaction with shape was not significant $[F(4,96)=1.70$, $\left.M S_{\mathrm{e}}=632, p>.15\right]$. The square/cross without segregation, like the triangle/arrow with no segregation, produced priming effects at the shortest duration of $40 \mathrm{msec}$, indicating an early, rapid grouping. These findings suggest that shape goodness did not influence the time course of grouping; whether grouping into a shape was early and rapid or slow and late depended on the processes involved in the grouping.

It should be noted that since the square/cross cannot be discriminated easily on the basis of part of their configuration, the convergence of the results for the square/cross with those for the triangle/arrow support our claim that the effects found for the triangle/arrow in Experiment 1 were not due to a partial representation of the configuration but, rather, to representation of the global form.

There was, however, one difference between the priming effects for the two types of shapes. In contrast to the triangle and arrow in Experiment 1, the priming effects observed for the square/cross without segregation and for the disconnected square/cross did not intensify with time. This resembled the early and stable priming effects found for grouping into columns/rows by common lightness in Experiment 1. It is possible that simple, or "good," shapes have an initial consolidated representation. Indeed, since the Gestalt psychologists have demonstrated that symmetry is a crucial organizing principle of shape (Wertheimer, 1923/1955), it has been corroborated that the perceptual system has a bias toward regularity and symmetry, thus preferring equilateral triangles and squares over other triangles and quadrilaterals (Feldman, 2000). Furthermore, it has been suggested that regular forms, such as a square, are treated as prototypes of their category, whereas other shapes are treated as distortions from the canonical form (e.g., Carmichael, Hogan, \& Walter, 1932; Leyton, 1984). Accordingly, the square may be fully perceived as early as $40 \mathrm{msec}$, whereas the isosceles triangle, which is distant from its equilateral prototype, may require time for consolidating the grouped representation. Note that this holds true also for the line configurations: The representation of the square does not evolve with time, although disconnected, but the representation of the triangle intensifies with time, despite its connectedness.

\section{GENERAL DISCUSSION}

The results of the present experiments clearly show that the time course of grouping depends on the processes involved in the grouping and the conditions prevailing for each process. Grouping involving shape formation was accomplished early and rapidly when no segregation of some elements from other elements was involved. Shape goodness in this case had no effect on how early the grouping was evident but had an effect on the evolvement of the per- cept: Whereas relatively "good" shapes (i.e., square/cross) had stable representations throughout the time course, relatively "poorer" shapes (i.e., triangle/arrow) consolidated with time. When segregation of some elements from other elements was involved (as in grouping by common lightness), grouping occurred early and rapidly if there was no need to resolve figure-ground relations among segregated units, as in the grouping into columns/rows. Grouping that required resolving figure-ground relations among segregated units, as in the grouping into a shape (a square/cross or a triangle/arrow) by common lightness, consumed time regardless of shape goodness.

One may argue that the slower emergence of grouping observed for the groupings into a shape by common lightness was not due to figure-ground resolution but, rather, to factors that could have influenced the "visibility" of the target elements. Indeed, in both experiments, the conditions requiring figure-ground resolution (i.e., grouping into a triangle/arrow or a square/cross by common lightness) also involved more elements than did the other conditions; also, in comparison with grouping into columns/rows by common lightness, they involved higher element density, and the white elements outnumbered the black ones. However, both present and previous findings do not support this alternative account. First, in the present study, number of elements in the columns/rows by common lightness condition was twice as many as in the triangle/arrow without segregation condition, and yet no difference between the emergence of grouping was observed. In both conditions, priming effects were evident at the shortest, 40-msec duration. Second, previous findings show that a larger number of elements does not necessarily slow grouping, and it may even speed it. For example, using the primed-matching paradigm, Kimchi (1998) has shown that grouping many, relatively small elements into a global configuration was rapid, whereas grouping of few, relatively large elements consumed time. Studies of texture segmentation, in which, by definition, displays of many elements have been used, have demonstrated rapid and effortless segregation of a region from the remainder of the textured pattern, depending on the similarity and difference between texture elements (e.g., Beck, 1982; Julesz, 1986). Furthermore, some visual search studies have demonstrated a faster search rate with increasing display size and element density in pop-out tasks (Bacon \& Egeth, 1991; Sagi \& Julesz, 1987), a finding attributed to grouping of the distractors (Bacon \& Egeth, 1991). Similarly, increasing the number of distractors improved performance when the distractors formed perceptual groups separately from the target (Banks \& Prinzmetal, 1976). Also, a crowding effect, in which perception of a target stimulus is impaired when surrounded by other stimuli, was reduced with an increase in the number of distractors when the target was a salient feature singleton (Põder, 2006). Third, masking of the black elements by the white ones is also not very plausible. Metacontrast masking, in which the target and the mask are spatially close but do not overlap (as was the case with our white and black elements) usually takes place when the stimulus onset asynchrony between the target and the mask is about $80 \mathrm{msec}$ (e.g., 
Breitmeyer, 1984; Reeves, 1982). However, the black and the white elements in the prime appeared simultaneously. The common onset masking, in which the target and the mask appear simultaneously, occurs if the mask persists beyond target offset (Enns \& Di Lollo, 2000). Yet there was no difference in the offset of the black and the white elements in our primes. Therefore, the slower emergence of priming in the grouping into a shape by common lightness cannot be accounted for by reduced visibility due to total amount of elements, elements density, or masking. ${ }^{1}$ Rather, it is most likely due to the requirement to resolve figure-ground relations.

The finding that grouping into a distinctive shape (a triangle/arrow or a square/cross) can emerge under certain conditions as early as grouping into lines (i.e., columns or rows) is perhaps not surprising. Previous findings suggest that arrows and triangles (Pomerantz et al., 1977) and, likewise, squares and crosses (Kimchi, 1994) are probably not perceived by conjoining previously extracted line segments; rather, it appears that the perception of these shapes is dominated by configural properties. The mechanisms underlying these findings, however, are yet to be understood.

As was noted earlier, the same types of organizations as those in the present experiments were examined in a previous study under inattention (Kimchi \& Razpurker-Apfeld, 2004). Comparing the findings from both studies appears to suggest that grouping that can take place without attention is also achieved early and rapidly, whereas grouping that requires attention also consumes time. Thus, grouping into columns/rows by common lightness/color occurred early, rapidly, and under inattention. On the other hand, grouping into a shape by common lightness/color consumed time and demanded attention, regardless of shape goodness. There is, however, one discrepancy between the time course results and the inattention results. Whereas grouping into a shape that did not involve segregation was observed early in time for both "good" shapes (i.e., square/cross) and relatively "poor" shapes (i.e., triangle/ arrow), the "good" shapes were grouped under inattention, but grouping of the "poorer" shapes was weak under inattention. Note that these relatively "poor" shapes were weakly perceived under inattention, although displayed for $200 \mathrm{msec}$, but showed a representation of the global form as early as $40 \mathrm{msec}$ under full attention, which nevertheless kept on consolidating throughout time. That is, grouping into a relatively "poor" shape when no segregation was involved appeared to demand attention but, under conditions of full attention, was achieved rapidly. On the other hand, grouping into a shape when segregation was involved consumed time even under full attention. Taken together, these findings suggest that although attentiondemanding grouping tends to consume time, this is not always the case. Further research is required to better understand and directly examine the relationship between attentional demands and time course of grouping.

This study demonstrated that the time course of grouping depends not only on the Gestalt principle that guides the grouping, as has been previously shown (e.g., Ben-Av $\&$ Sagi, 1995; Kurylo, 1997), but also on the processes involved in the grouping and the conditions prevailing for each process. Different time courses were found in the present study even when grouping was guided by the same Gestalt principle. Our findings suggest that segregation (at least one based on common lightness) and shape formation (at least for the shapes used in the present study) can occur rapidly but that, when resolving figure-ground relations between segregated units is called for, presumably because of conflicting determinants of figure-ground differentiation, grouping consumes time. Note, however, that the requirement to resolve figure-ground relations need not be necessary for a grouping to be time consuming. For example, grouping into columns/rows could occur more slowly were it based on common form, rather than common lightness. Although there is no necessary correspondence between microgenesis and ontogenesis (Hadad \& Kimchi, 2006), infant research demonstrating that grouping based on common lightness emerges more readily than that based on common form in early development (Quinn \& Bhatt, 2006) is suggestive of this possibility. Shape goodness appears to be not crucial for the early emergence of grouping, but we should be somewhat cautious about this conclusion in light of the relatively narrow range of goodness used in our study. ${ }^{2}$ It is possible that a wider range of goodness would have yielded an effect.

Our finding of rapid grouping for both connected line configurations (a triangle and an arrow; Experiment 1) and disconnected line configurations (a square and a cross; Experiment 2) converge with previous findings (e.g., Hadad \& Kimchi, 2006; Kimchi, 1998, 2000) suggesting that, contrary to Palmer and Rock's (1994) proposal, uniform connectedness may not play a crucial role in early perceptual organization.

Finally, the present results converge with previous findings (e.g., Behrmann \& Kimchi, 2003; Kimchi, 1998) in supporting the view that grouping is not a unitary process, as has been assumed by traditional theories of perception, but, rather, a multiplicity of processes varying in attentional demands (e.g., Kimchi \& Razpurker-Apfeld, 2004) and in time course.

\section{AUTHOR NOTE}

This research was conducted at the Institute of Information Processing and Decision Making, University of Haifa, and was partly based on the first author's dissertation under the supervision of the second author. We are indebted to Yafa Lev for programming the experiments and to Anat Hershkovitz for assistance in data collection. We thank Jim Pomerantz, Lana Trick, and an anonymous reviewer for useful comments on an earlier version of the manuscript. Correspondence should be addressed to R. Kimchi, Department of Psychology, University of Haifa, Haifa 31905, Israel (e-mail: rkimchi@research.haifa.ac.il).

\section{REFERENCES}

BACON, W. F., \& Egeth, H. E. (1991). Local processes in preattentive feature detection. Journal of Experimental Psychology: Human Perception \& Performance, 17, 77-90.

Banks, W. P., \& Prinzmetal, W. (1976). Configurational effects in visual information processing. Perception \& Psychophysics, 19, 361-367.

BeCK, J. (1982). Textural segmentation. In J. Beck (Ed.), Organization and representation in perception (pp. 285-317). Hillsdale, NJ: Erlbaum. 
Behrmann, M., \& Kimchi, R. (2003). What does visual agnosia tell us about perceptual organization and its relationship to object perception? Journal of Experimental Psychology: Human Perception \& Performance, 29, 19-42.

BeLLER, H. K. (1971). Priming: Effects of advance information on matching. Journal of Experimental Psychology, 87, 176-182.

Ben-Av, M. B., \& SAGI, D. (1995). Perceptual grouping by similarity and proximity: Experimental results can be predicted by intensity autocorrelations. Vision Research, 35, 853-866.

Breitmeyer, B. G. (1984). Visual masking: An integrative approach. Oxford: Oxford University Press, Clarendon Press.

Carmichael, L., Hogan, H. P., \& Walter, A. A. (1932). An experimental study of the effect of language on the representation of visually perceived form. Journal of Experimental Psychology, 15, 73-86.

ENNS, J. T., \& Di Lollo, V. (2000). What's new in visual masking? Trends in Cognitive Sciences, 4, 345-352.

Farroni, T., Valenza, E., Simion, F., \& Umiltà, C. (2000). Configural processing at birth: Evidence for perceptual organization. Perception, 29, 355-372.

Feldman, J. (2000). Bias toward regular form in mental shape spaces. Journal of Experimental Psychology: Human Perception \& Performance, 26, 1-14.

GARNER, W. R. (1974). The processing of information and structure. Potomac, MD: Erlbaum.

Gillam, B. (2005). Observations on associative grouping (in honor of Jacob Beck). Spatial Vision, 18, 147-157.

Hadad, B.-S., \& KimchI, R. (2006). Developmental trends in utilizing perceptual closure for grouping of shape: Effects of spatial proximity and collinearity. Perception \& Psychophysics, 68, 1264-1273.

HAN, S. (2004). Interactions between proximity and similarity grouping: An event-related brain potential study in humans. Neuroscience Letters, 367, 40-43.

Julesz, B. (1986). Texton gradients: The texton theory revisited. Biological Cybernetices, 54, 245-251.

KIмCHI, R. (1994). The role of wholistic/configural properties versus global properties in visual form perception. Perception, 23, 489-504.

KIMCHI, R. (1998). Uniform connectedness and grouping in the perceptual organization of hierarchical patterns. Journal of Experimental Psychology: Human Perception \& Performance, 24, 1105-1118.

KimCHI, R. (2000). The perceptual organization of visual objects: A microgenetic analysis. Vision Research, 40, 1333-1347.

Kimchi, R., Hadad, B.-S., Behrmann, M., \& Palmer, S. E. (2005). Microgenesis and ontogenesis of perceptual organization: Evidence from global and local processing of hierarchical patterns. Psychological Science, 16, 282-290.

KIMCHI, R., \& RAZPURKER-APFELD, I. (2004). Perceptual grouping and attention: Not all groupings are equal. Psychonomic Bulletin \& Review, 11, 687-696.

KoffKA, K. (1935). Principles of Gestalt psychology. New York: Harcourt, Brace \& World.

Kovacs, I. (2000). Human development of perceptual organization. Vision Research, 40, 1301-1310.

KuryLo, D. D. (1997). Time course of perceptual grouping. Perception \& Psychophysics, 59, 142-147.

Leyton, M. (1984). Perceptual organization as nested control. Biological Cybernetics, 51, 141-153.

MARR, D. (1982). Vision: A computational investigation into the human representation and processing of visual information. San Francisco: Freeman.

NeIsser, U. (1967). Cognitive psychology. New York: AppletonCentury-Crofts.

Palmer, S. E. (1991). Goodness, Gestalt, groups, and Garner: Local symmetry subgroups as a theory of figural goodness. In G. R. Lockhead \& J. R. Pomerantz (Eds.), The perception of structure: Essays in honor of Wendell R. Garner (pp. 23-39). Washington, DC: American Psychological Association.
Palmer, S. E. (1992). Common region: A new principle of perceptual grouping. Cognitive Psychology, 24, 436-447.

PALMER, S. [E.], \& Rock, I. (1994). Rethinking perceptual organization: The role of uniform connectedness. Psychonomic Bulletin \& Review, 1, 29-55.

Peterson, M. A. (2003). On figures, grounds, and varieties of surface completion. In R. Kimchi, M. Behrmann, \& C. R. Olson (Eds.), Perceptual organization in vision: Behavioral and neural perspectives (pp. 87-116). Mahwah, NJ: Erlbaum.

PõDER, E. (2006). Crowding, feature integration, and two kinds of "attention." Journal of Vision, 6, 163-169.

Pomerantz, J. R., Sager, L. C., \& Stoever, R. J. (1977). Perception of wholes and of their component parts: Some configural superiority effects. Journal of Experimental Psychology: Human Perception \& Performance, 3, 422-435.

QuinN, P. C., \& BHATt, R. S. (2005). Good continuation affects discrimination of visual pattern information in young infants. Perception \& Psychophysics, 67, 1171-1176.

Quinn, P. C., \& BhatT, R. S. (2006). Are some Gestalt principles deployed more readily than others during early development? The case of lightness versus form similarity. Journal of Experimental Psychology: Human Perception \& Performance, 32, 1221-1230.

Quinn, P. C., Bhatt, R. S., Brush, D., Grimes, A., \& Sharpnack, H. (2002). Development of form similarity as a Gestalt grouping principle in infancy. Psychological Science, 13, 320-328.

QuinN, P. C., Burke, S., \& Rush, A. (1993). Part-whole perception in early infancy: Evidence for perceptual grouping produced by lightness similarity. Infant Behavior \& Development, 16, 19-42.

ReEves, A. (1982). Metacontrast U-shaped functions derive from two monotonic processes. Perception, 11, 415-426.

Rich, A., \& Gillam, B. (2000). Failure to detect changes in color for lines rotating in depth: The effects of grouping and type of color change. Vision Research, 40, 1469-1487.

Rock, I. (1986). The description and analysis of object and event perception. In K. R. Boff, L. Kaufman, \& J. P. Thomas (Eds.), Handbook of perception and human performance (Vol. II, pp. 33.1-33.71). New York: Wiley.

Rubin, E. (1921). Visuell wahrgenommene Figuren. Copenhagen: Glydenalske boghandel.

Russell, C., \& Driver, J. (2005). New indirect measures of "inattentive" visual grouping in a change-detection task. Perception \& Psychophysics, 67, 606-623.

SaGI, D., \& Julesz, B. (1987). Short-range limitation on detection of feature differences. Spatial Vision, 2, 39-49.

Sekuler, A. B., \& Palmer, S. E. (1992). Perception of partly occluded objects: A microgenetic analysis. Journal of Experimental Psychology: General, 121, 95-111.

Treisman, A. (1982). Perceptual grouping and attention in visual search for features and for objects. Journal of Experimental Psychology: Human Perception \& Performance, 8, 194-214.

TRICK, L. M., \& ENNs, J. T. (1997). Clusters precede shapes in perceptual organization. Psychological Science, 8, 124-129.

Wertheimer, M. (1955). Gestalt theory. In W. D. Ellis (Ed.), A source book of Gestalt psychology (pp. 1-16). London: Routledge \& Kegan Paul. (Original work published in German, 1923)

\section{NOTES}

1. Note that even when we reduced the contrast in the prime by using blue and yellow elements, instead of black and white ones, and the elements were grouped into triangle/arrow by common color, the findings were replicated: Priming effects were observed relatively late.

2. We thank Jim Pomerantz for bringing this point to our attention.

(Manuscript received April 7, 2006;

revision accepted for publication November 27, 2006.) 